Research Article

\title{
A Wind Turbine Emulator Using Field-Oriented Induction Motor
}

\author{
Yi-Chun Hsu, Min-Ze Lu, Chang-Ming Liaw *
}

Department of Electrical Engineering, National Tsing Hua University, Hsinchu, Taiwan, ROC; E-Mails: e098926@yahoo.com.tw; b10112016@gmail.com; cmliaw@ee.nthu.edu.tw

* Correspondence: Chang-Ming Liaw; E-Mail: cmliaw@ee.nthu.edu.tw

Academic Editor: Aritra Ghosh

Special Issue: Progress of Wind Energy Technology and Its Maintenance

Journal of Energy and Power Technology

2021, volume 3, issue 2

doi:10.21926/jept.2102018
Received: December 18, 2020

Accepted: April 09, 2021

Published: April 28,2021

\begin{abstract}
This paper proposes a Wind Turbine Emulator (WTE) using an Indirect Field Oriented (IFO) Induction Motor (IM). The IM drive can be controlled as a conventional prime mover in speed mode, or a wind turbine in torque-speed mode via robust observed torque control. This paper presents key issues for establishing a high-performance IFO IM drive. Further, this study develops a wind turbine load Interior Permanent-Magnet Synchronous Generator (IPMSG) followed by a three-phase Vienna Switch-Mode Rectifier (SMR). It receives mechanical driven power from the WTE and establishes a $400 \mathrm{~V}$ DC-link for the DC micro-grid. The good generating characteristics are achieved through proper controls of both the IPMSG and SMR. Various wind turbine torque-speed and power-speed characteristic curves under different wind speeds can be emulated by the developed WTE. The designed results are verified by simulations. The measured results indicate that the errors are within $1.5 \%$ and $1.0 \%$, respectively, for the torque and the power compared to the designed ones. The maximum power point tracking (MPPT) function with good performance for the PMSG with Vienna SMR is achieved using the perturb and observation (P\&O) approach. The dynamic and steady-state operating characteristics of the developed whole turbine emulator driven PMSG system are assessed experimentally.
\end{abstract}

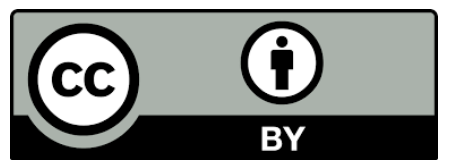

(C) 2021 by the author. This is an open access article distributed under the conditions of the Creative Commons by Attribution License, which permits unrestricted use, distribution, and reproduction in any medium or format, provided the original work is correctly cited. 


\section{Keywords}

Wind turbine; emulator; induction motor; switch-mode rectifier; torque control; current control; speed control; maximum power point tracking

\section{Introduction}

In recent years, renewable energy sources [1-4] are being utilized to reduce fossil fuel consumption. A photovoltaic cell and wind generator are the most popularly used renewable sources. Some interconnected applications for wind turbines with grid, energy storage systems, and electric vehicles were presented [5-8]. The survey for comparative characteristics of various types of wind generators and their interface power converters has been given in an earlier study [9]. Owing to the high power density, the PMSG is chosen as the wind generator for testing the developed turbine emulator. The proper commutation is set to effectively use the reluctance power component.

In order to facilitate the research on wind generating systems, a wind turbine emulator (WTE) is needed. Many studies have proposed suitable WTEs for various wind generator system characteristics [10-13]. Basically, any electric motor [14, 15] can be employed to construct a WTE. Some WTEs using permanent-magnet synchronous motor (PMSM) $[16,17]$ and induction motor [1823] have been developed. However, the WTE with desirable wind generating characteristics is not easy to achieve. Compared to other electric motors, IM has advantages of rigid structure, being magnet-free, low cost, ease of making field-weakening, suitability for high-speed operation, and a few more.

Basically, the high-performance induction motor drives can be classified into field-oriented control [24-27] and observed torque control [28, 29]. Both are sensitive to the changes in motor parameters; thus, they need accurate parameters. In the developed WTE, the indirect field-oriented (IFO) induction motor is employed with adequate field current setting and accurate motor parameters using the proposed measurement approach. The established motor drive can be operated in speed mode for a conventional prime mover or in torque mode for emulating a wind turbine.

SMR is a crucial active front-end for the plants drawing power from the AC sources. Earlier studies $[30,31]$ present the surveys for single-phase and three-phase SMRs. The three-phase Vienna SMR [31-34] provides the features of complete power factor PWM control flexibility using only three switches, lower switching losses for three-level voltage switching, and unidirectional power flow capability. For the established WTE system, the adoption in the load PMSG followed interface is for the unidirectional power requirement.

For a wind generating system, the application of the Maximum Power Point Tracking (MPPT) control extracts the maximum wind energy and converts it to electric energy using the generator. Earlier studies [35-39] proposed numerous MPPT algorithms. The designing of the P\&O control scheme is for the developed WTE-driven wind PMSG with followed Vienna SMR.

This paper proposes a developed wind turbine emulator established using an IFO induction motor. The designed wind turbine torque-speed and power-speed characteristics according to the specific wind turbine mechanical data and the employed IM ratings are presented and verified by 
simulation and measured results. The developed WTE can drive any category of the generator. IPMSG with Vienna SMR coupled to the turbine emulator shaft serves as its test load. The emulator controlling is similar to the desirable conventional turbine and wind turbine, which is done by the properly designed IFO IM drive with robust observed torque control. The verification of the operating characteristics of the established IM drive-based WTE and the PMSG based wind generator is experimentally done.

\section{System Configuration}

Figure 1 depicts the typical configuration system of a DC micro-grid. All wind generators, PV sources, and energy stored devices must be interfaced to the common DC bus by suited AC/DC or DC/DC converters. Further, the bus using DC/DC converters or inverters powers the loads. An electrical vehicle (EV) and the specific battery energy storage systems (BESS) can be incorporated into the micro-grid for exchanging their energies and enhancing the supplying power quality of micro-grid. In addition, the DC micro-grid can be connected to the utility grid using a bidirectional inverter through a synchronization process.

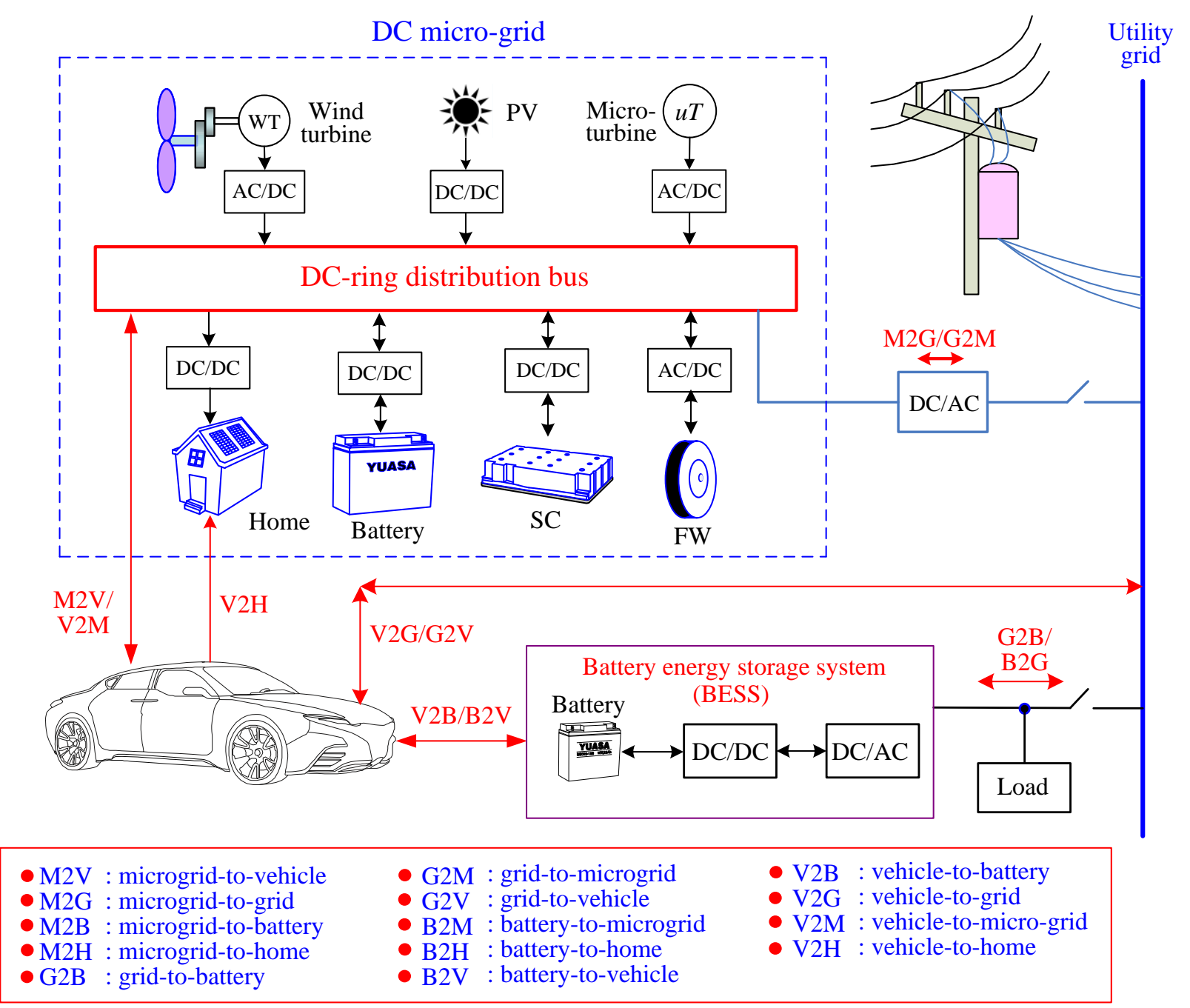

Figure 1 Typical system configuration of a DC micro-grid incorporated with EV and BESS. 
Among the most employed renewable sources are the wind-generators. Figure 2 shows a typical wind $A C$-generator with a fully-rated converter. $A$ back-to-back $A C / A C$ converter connects the stator of a wind turbine-driven induction generator (IG) or PMSG to the grid.

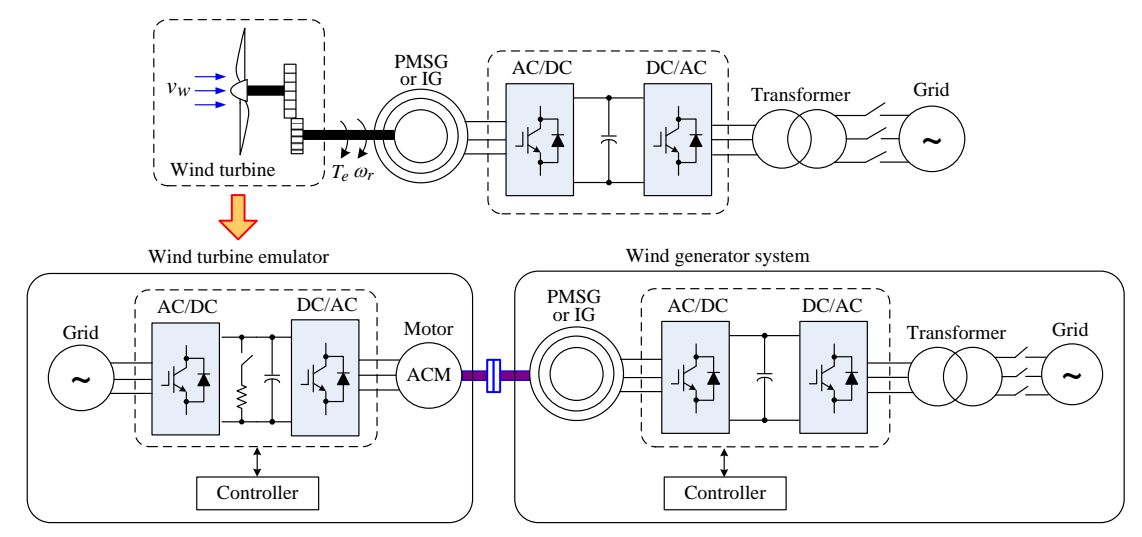

Figure 2 Typical configuration of a wind turbine emulator-driven generator system.

Emulating the wind generator system, depicted in the upper part of Figure 2, requires a turbine emulator and a test load generator. The lower panel in Figure 2 illustrates the typical configuration of a wind turbine emulator-driven generator system. Any category of the motor can be the actuator of the turbine emulator. In the developed emulator, the IM is adopted. The key issues for IM IFO mechanism, current and speed controls, and robust observed torque control are well addressed. The developed IM drive can successfully act as a conventional fixed-speed prime mover or a variable-speed wind turbine. The developed WTE can drive any category of the wind generator. An IPMSG is used as the load generator, which is followed by a unidirectional Vienna SMR.

$A$ wind generator following $A C / D C$ converter requires only unidirectional power, and consequently, the Vienna SMR possesses the best-compromised characteristics. First, only three power switches are required to achieve sinusoidal armature current waveform with nearly unity power factor and low THDi. Next, the inherent three-level voltage switching yields lower switching losses. Lastly, the inherent bipolar DC voltage output can naturally establish the microgrid bipolar DC bus.

Figure 3 shows the developed wind turbine emulator-based IM drive. The turbine emulator shaft coupled to IPMSG followed by Vienna SMR serves as the test load. Figure 4 depicts the control scheme of the IFO induction motor drive. 


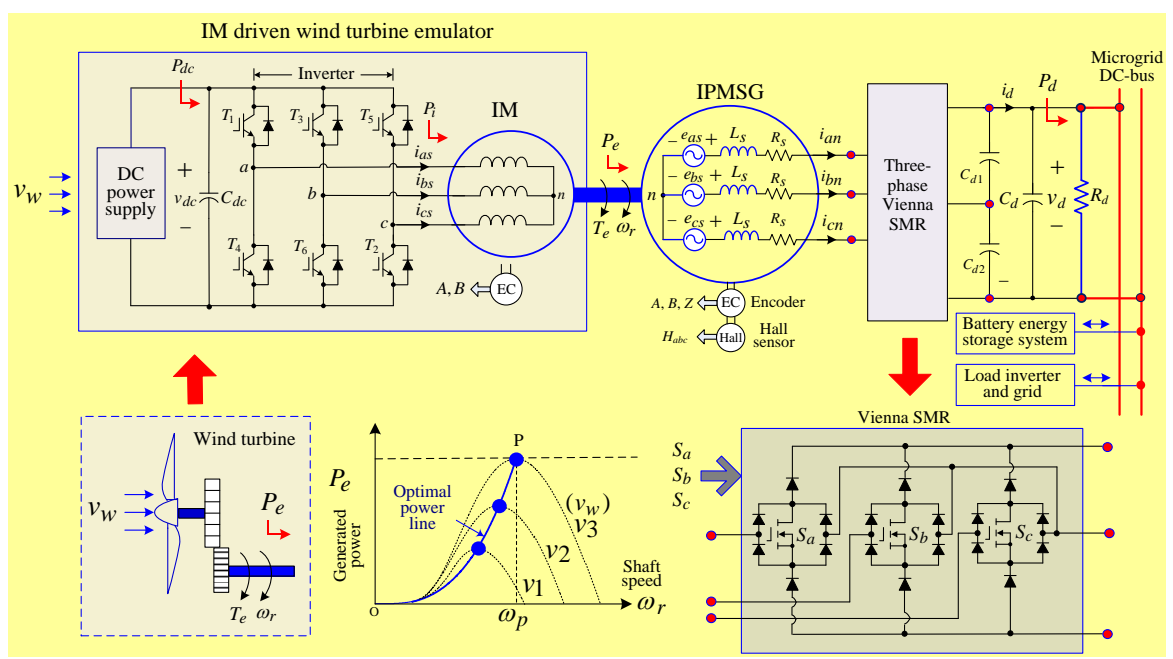

Figure 3 The developed induction motor-based wind turbine emulator driven IPMSG system.

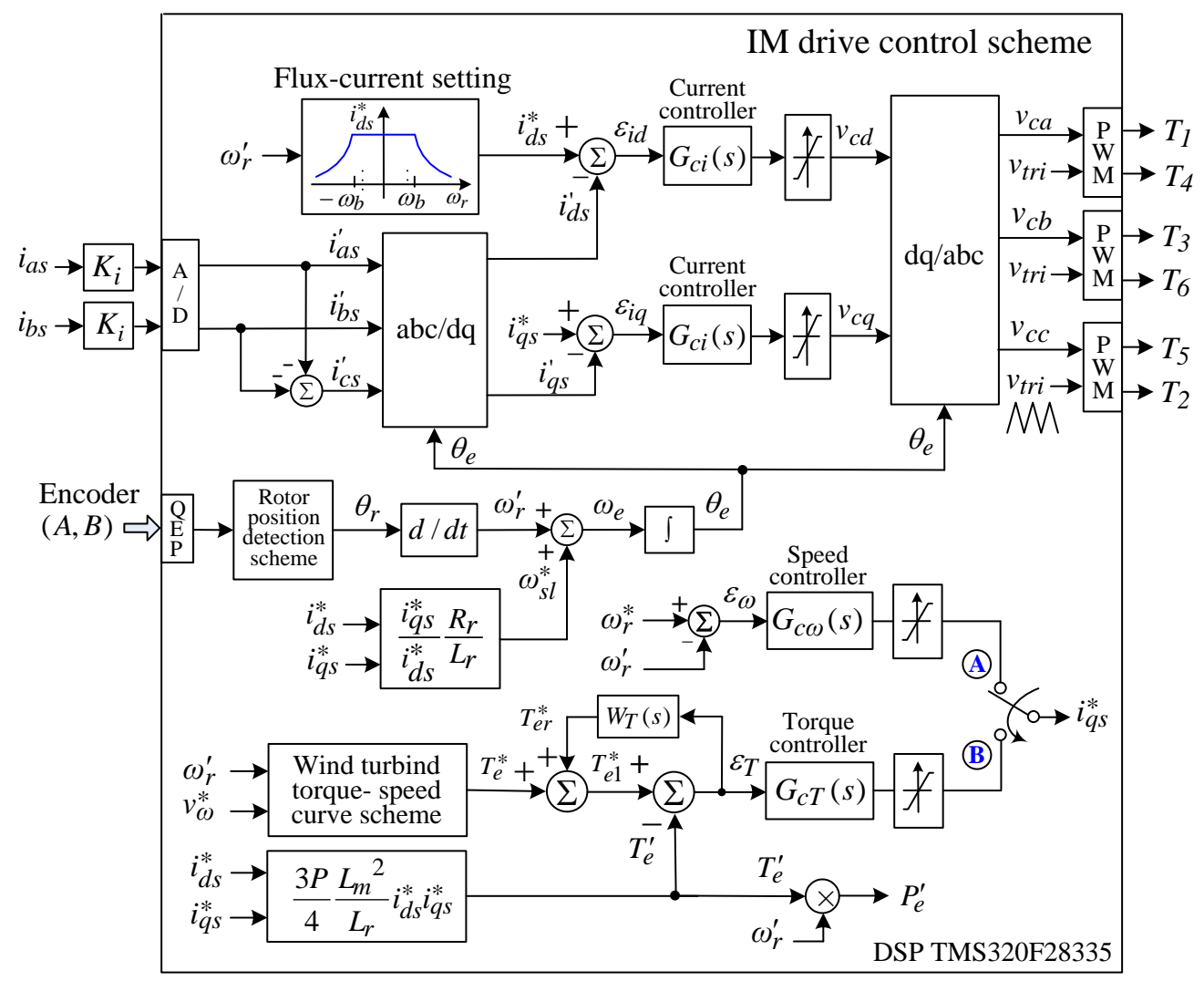

Figure 4 Control scheme of the developed prime mover emulator IFO induction motor drive.

As depicted in Figure 4, the IM driven emulator can operate as a conventional prime mover in speed mode or torque mode for wind turbine:

(1) Speed mode: Placing the switch in Figure 4 at position (A). The outer speed loop yields the torque current command $i_{q s}^{*}$.

(2) Torque mode: Placing the switch at position (B). Regulating the tracking error between the observed torque $T_{e}^{\prime}$ and its command $T_{e}^{*}$ provide the command $i_{q s}^{*}$, generated by the modeled wind 
torque-speed curve to represent the wind turbine driving behavior. Properly set slip angular speed command and the field-current command $i_{d s}^{*}$ allow high torque development in the IFO IM drive.

The developed WTE can be employed to drive any types of generator. In order to test the developed wind turbine emulator, a load PMSG followed by Vienna SMR, as shown in Figure 3, is constructed to establish the DC microgrid common DC-bus voltage with proper regulation. A load resistor across the bus is used for the test load. The designed PMSG system can be controlled under the voltage mode for the conventional generator or the MPPT mode for the wind generator. While conducting the MPPT control, the maximization of the Vienna SMR DC-link power $P_{d}$ is achieved.

\section{Induction Motor Driven Wind Turbine Emulator}

\subsection{Power Circuit}

a. Induction motor: Rating on the employed motor is $4-$ pole, $60 \mathrm{~Hz}, 150 \mathrm{~V}, 2.2 \mathrm{~kW}, 10.4 \mathrm{~A}$, and $1740 \mathrm{rpm}$.

b. Velocity sensing scheme: The incremental encoder $(A, B, Z)$ signals with 1000pluses/rev yield the sensed rotor speed.

c. PWM inverter: Constructed using three IGBT modules CM100DY-12H (Mitsubishi, $V_{C E S}=600 \mathrm{~V}$, $I_{C}=100 \mathrm{~A}$ (continuous), and $I_{C}=200 \mathrm{~A}$ (pulsed)).

d. Inverter input source: The DC-link of motor drive inverter is powered using commercialized DC power supply with $v_{d c}=400 \mathrm{~V}$. If the WTE powered by the mains is desired, one can adopt a SMR front-end. The Vienna SMR may also be a good choice for the reasons of unidirectional power requirement and the least power switch number being used in achieving good line drawn power quality.

\subsection{Indirect Field-Oriented Mechanism}

For an IFO induction motor, setting the following slip angular command achieves decoupling control:

$$
\omega_{s 1}^{*}=\frac{R_{r}}{L_{r}} \frac{i_{q s}^{*}}{i_{d s}^{*}} \triangleq \frac{1}{T_{r}} \frac{i_{q s}^{*}}{i_{d s}^{*}}
$$

Here $R_{r}$ is rotor resistance per-phase, $L_{r}$ is rotor inductance per-phase, and $T_{r}$ is rotor timeconstant. Setting the actual rotor parameters in the field-orientation scheme can result in the following phenomena: (i) $\lambda_{q r}=0$ and $d \lambda_{q r} / d t=0$; (ii) The rotor flux becomes $\lambda_{r}^{*}=\lambda_{d r}^{*}=$ $\left(L_{m} i_{d s}^{*}\right) /\left(1+s T_{r}\right) \approx L_{m} i_{d s}^{*}$, as the electric time-constant $T_{r}$ is generally much smaller to the mechanical time constant; and (iii) The induction motor developed torque, and the mechanical equation is as follows:

$$
T_{e}=\left(\frac{3 P}{4} \frac{L_{m}^{2}}{L_{r}} i_{d s}^{*}\right) i_{q s}^{*}=T_{L}+B \omega_{r}+J \frac{d}{d t} \omega_{r}
$$

Here $P$ is pole number, $\boldsymbol{L}_{\boldsymbol{m}}$ is magnetizing inductance, $T_{L}$ is load torque, $B$ is total damping coefficients, and $J$ is total inertia-constant. 
- D-axis current setting: Using the rated data and the measured NLT data, the d-axis current commands become:

$\omega_{r} \leq \omega_{b}\left(\omega_{b}=\right.$ base speed $)$ :

$$
\begin{gathered}
i_{d s}^{*}=i_{d s b}^{*}=\frac{\sqrt{2}\left(\frac{V_{l, \text { rated }}}{\sqrt{3}}\right)-i_{q s, N L} R_{s}}{L_{s} \omega_{e}} \approx \frac{\sqrt{2}\left(\frac{V_{l, \text { rated }}}{\sqrt{3}}\right)}{L_{s}\left(\frac{P \pi}{60} \frac{N_{\text {rated }}}{1-S_{\text {rated }}}\right)} \\
\omega_{r}>\omega_{b}: i_{d s}^{*}=\frac{i_{d s b}^{*}}{\omega_{r, p u}}, \omega_{r, p u}=\frac{\omega_{r}}{\omega_{b}}
\end{gathered}
$$

Here the simple $\mathbf{1} / \boldsymbol{\omega}_{\boldsymbol{r}}$ field-weakening approach is adopted. The rated line-to-line voltage $V_{\text {rated }}=$ $150 \mathrm{~V}$ and $i_{q s, N L} R_{s}$ are neglected owing to their small value at no load, $S_{\text {rated }}$ is the rated slip, known from the given ratings of an induction motor, and $N_{\text {rated }}$ is the rated rotor speed.

\subsection{Induction Motor Parameter Estimation}

It is well-known that the IFO control behavior for an IM is greatly affected by the field current command $i_{d s}^{*}$ and the rotor parameters set in the $\omega_{s l}^{*}$. The observed torque for torque mode control is also related to the parameters $L_{m}$ and $L_{r}$.

Normally, the IM phase equivalent circuit parameters are measured from the no-load test (NLT) under rated voltage and frequency, and the blocked-rotor test (BRT) with reduced frequency. However, the commercialized AC power supply with sufficiently low frequency is not readily available. To overcome this difficulty, a parameter estimation mechanism is proposed (Figure 5(a) to $5(\mathrm{c})$ ), where the constructed inverter (Figure 3) performs the NLT under the voltage-mode with rated flux and the BRT under current-mode with rated current and sufficiently low frequency.

Measured Results: The blocked-rotor test measured a-phase armature current under $10.34 \mathrm{~A}$ $(\mathrm{RMS}) / 5 \mathrm{~Hz}$, and Figure $5(\mathrm{~d})$ shows the plotted command with a very close current tracking waveform. All measured data are listed below:

- DC-test: $R_{S}=0.8 \Omega$.

- NLT: $V_{n l}=150.14 \mathrm{~V} / 60 \mathrm{~Hz}, I_{n l}=4.913 \mathrm{~A}, P_{n l}=82.68 \mathrm{~W}$.

- $\quad$ BRT: $V_{b r}=25.13 \mathrm{~V} / 5 \mathrm{~Hz}, I_{b r}=10.34 \mathrm{~A}, P_{b r}=415.14 \mathrm{~W}$.

Using the data, following the standard estimation procedure, the estimated equivalent circuit parameters are:

$R_{s}=0.8 \Omega, R_{r}=0.4943 \Omega, L_{l s}=4.3098 \mathrm{mH}, L_{m}=42.488 \mathrm{mH}, L_{l r}=4.3098 \mathrm{mH}, L_{r}=46.7978 \mathrm{mH}$. 


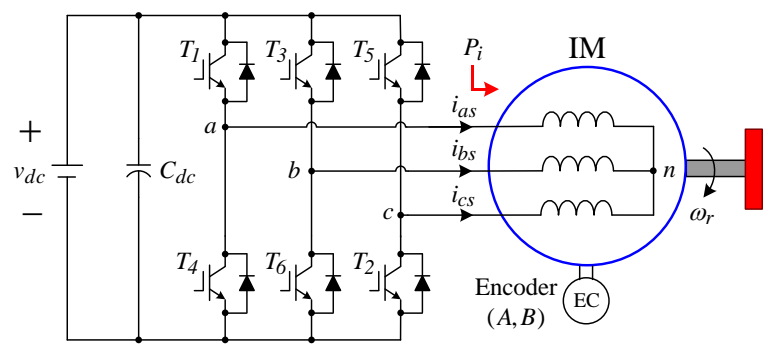

(a)

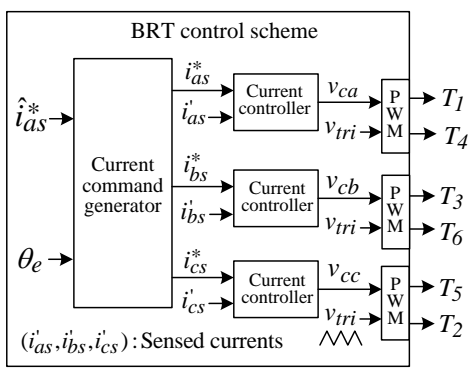

(c)

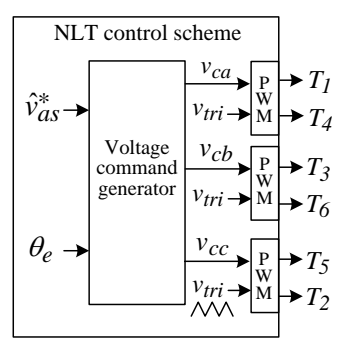

(b)

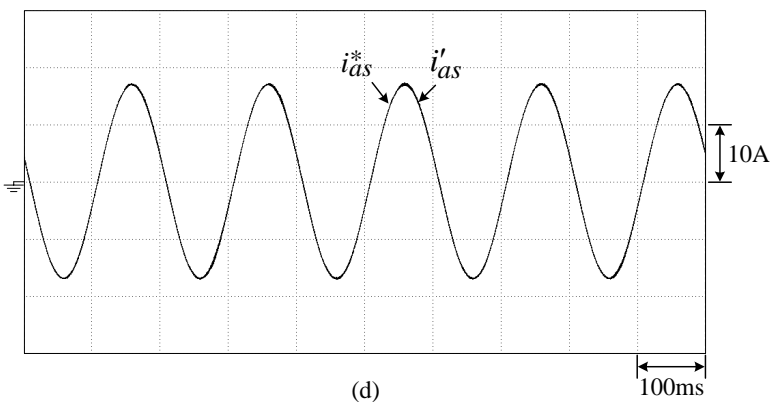

(d)

Figure 5 The proposed induction motor inverter-fed parameter estimation mechanism:

(a) Schematic; (b) NLT scheme; (c) BRT scheme; (d) BRT measured results at $5 \mathrm{~Hz}$.

\subsection{Control Schemes}

The design procedures of all controllers are neglected due to the limit of scope. The summary of designed controllers is as follows:

\subsubsection{Ramp-Comparison Current Controlled PWM Scheme}

The current loop control block of the developed standard IM drive in $d$-q domain is shown in Figure 4. And the ramp-comparison current-controlled PWM (RC-CCPWM) scheme is adopted here. Both the d-axis and q-axis current feedback controllers are set to be identical with

$$
G_{c i}(s)=K_{P i}+\frac{K_{I i}}{s}
$$

The upper limit of $K_{P i}$ is found first using large signal stability criterion expressed as follows:

$$
\frac{d}{d t} v_{c q} \leq \frac{d v_{t r i}}{d t}
$$

By letting $G_{c i}=K_{P i}$, Figure 4 and equation (6) provides the following equation:

$$
\left(\frac{d v_{c q}}{d t}=\frac{d \varepsilon i_{q s}}{d t} K_{P i}=\frac{v_{q s}}{L_{s}} K_{i} K_{P i}\right) \leq \frac{d v_{t r i}}{d t}
$$

The related system parameters of the established motor drive are switching frequency $f_{s}=20$ $\mathrm{kHz}, d v_{t r i} / d t=40 \mathrm{kV} / \mathrm{s}, K_{i}=0.05 \mathrm{~V} / \mathrm{A}, L_{d}=L_{q}=L_{l s}+L_{m}=46.8 \mathrm{mH}, V_{d c}=400 \mathrm{~V}$, and $v_{q s}=$ $V_{d c} / 2=200 \mathrm{~V}$. Using the known parameters, the limit of $K_{p i}$ from equation (7) is as follows:

$$
K_{P i} \leq 187.2
$$


Accordingly, $K_{P i}=4.33$ and selection of integral gain by trial-and-error yields:

$$
G_{c i}(s)=K_{P i}+\frac{K_{I i}}{s}=4.33+\frac{50}{s}
$$

\subsubsection{Speed Feedback Controller}

For simplicity, the selected speed controller is also chosen to be PI type with its parameters being determined via trial-and-error as:

$$
G_{c \omega}(s)=K_{P \omega}+\frac{K_{I \omega}}{s}=4.5+\frac{6.47}{s}
$$

\subsubsection{Torque Controller}

Feedback Controller. The observed torque is obtained from equation (2), and the PI torque feedback controller is as follows:

$$
G_{c T}(s)=K_{P T}+\frac{K_{I T}}{s}=2.5+\frac{70.5}{s}
$$

Torque Robust Error Cancellation Controller (TRECC). To enhance the torque control robustness, a simple TRECC, as shown in Figure 4, is added with the robust weighting function being:

$$
W_{T}(s)=\frac{W_{T}}{1+\tau_{T} s}, 0 \leq W_{T} \leq 1
$$

where $\tau_{T}=1.592 \times 10^{-3} S$ is set. Through derivation one can find that the voltage tracking error $\varepsilon_{T}$ yielded by feedback control can only be reduced to $\left(1-W_{T}(s)\right) \varepsilon_{T} \approx\left(1-W_{T}\right) \varepsilon_{T}$ by adding the TRECC. However, the control effort $i_{q s}^{*}$ will be magnified to $i_{q S}^{*} /\left(1-W_{T}\right)$. Thus, the compromised state in control performance and resulting control effect must be considered.

\subsection{Modeling of Wind Turbine Output Characteristics}

Generally, the developed torque-speed $\left(T_{e}-\omega_{r}\right)$ and power-speed $\left(P_{e}-\omega_{r}\right)$ characteristics of a wind turbine depend on the specific mechanical design, especially the power coefficient. The known data provided from the vendor can be used to program the $\left(T_{e}-\omega_{r}\right)$ and $\left(P_{e}-\omega_{r}\right)$ curves for a wind turbine. Although the mathematical modeling is carried out by the assumed parameters, the derived modeling process is generalized and can easily be modified according to the specified data.

The programmed torque-speed $\left(T_{e}-\omega_{r}\right)$ curves for a given wind speed $v_{w}$ of the developed wind turbine emulator, from equation [1] are as follows:

$$
\begin{gathered}
T_{e}=\left(-K_{\max }\right) \omega_{r}^{2}+\left(2 K_{\max } \omega_{m t}\right) \omega_{r} \\
\omega_{m t}=100 v_{w}+200, \omega_{m t} \geq 700 \mathrm{rpm}
\end{gathered}
$$

Where $\omega_{r}$ is rotor speed in rpm, $v_{w}$ is wind-speed in $\mathrm{m} / \mathrm{s}$, and $\omega_{m t}$ is rotor speed in rpm at which the maximum torque occurs. The relationship in equation (14) is arbitrary. Besides, the 
determination of constant $K_{\max }$ is done at the rated speed (=1740rpm) and the rated torque $(=$ $12.07 \mathrm{~N} \cdot \mathrm{m}$ ) of the employed IM, which is as follows:

$$
K_{\max }=12.07 / 1740^{2}=3.986 \times 10^{-6} \mathrm{~N} \cdot \mathrm{m} /(\mathrm{rpm})^{2}
$$

The maximum torque under a wind speed $v_{w}$ is as follows:

$$
T_{\max }=K_{\max }\left(\omega_{m t}\right)^{2}=3.986 \times 10^{-6}\left(\omega_{m t}\right)^{2}
$$

The power-speed $\left(P_{e}-\omega_{r}\right)$ curves for a given wind speed $v_{w}$, from equation (13), is as follows:

$$
P_{e}=T_{e}\left(\frac{2 \pi}{60}\right) \omega_{r}(N-m) \cdot(r a d / s)
$$

The optimal power and the corresponding optimal torque $\omega_{r}=\omega_{\text {opt }}$ for a given wind speed $v_{w}$ are as follows:

$$
P_{o p t}=K_{o p t, p}\left(\omega_{o p t}\right)^{3}, T_{o p t}=K_{o p t, t}\left(\omega_{o p t}\right)^{2}, K_{o p t, t}=1.959 \times 10^{-6}, K_{o p t, p}=2.0919 \times 10^{-7}
$$

The relationship between $\omega_{m t}$ and $\omega_{\text {opt }}$ is:

$$
\omega_{o p t}=1.333 \omega_{m t}
$$

\subsubsection{The Designed Torque Curves}

From equations (13) and (14), using the related system parameters, the designed $T_{e}-\omega_{r}$ curves under various wind speeds are as follows:

$$
\begin{gathered}
T_{e}=-3.986 \times 10^{-6} \omega_{r}^{2}+0.005979 \omega_{r}, v_{w}=5.5 \mathrm{~m} / \mathrm{s} ; T_{e}=-3.986 \times 10^{-6} \omega_{r}^{2}+0.0067762 \omega_{r}, \mathrm{v}_{\mathrm{w}}=6.5 \mathrm{~m} / \mathrm{s} \\
T_{e}=-3.986 \times 10^{-6} \omega_{r}^{2}+0.007573 \omega_{r}, v_{w}=7.5 \mathrm{~m} / \mathrm{s} ; T_{e}=-3.986 \times 10^{-6} \omega_{r}^{2}+0.008371 \omega_{r}, v_{w}=8.5 \mathrm{~m} / \mathrm{s} \\
T_{e}=-3.986 \times 10^{-6} \omega_{r}^{2}+0.009168 \omega_{r}, v_{w}=9.5 \mathrm{~m} / \mathrm{s} ; T_{e}=-3.986 \times 10^{-6} \omega_{r}^{2}+0.009965 \omega_{r}, v_{w}=10.5 \mathrm{~m} / \mathrm{s} \\
T_{e}=-3.986 \times 10^{-6} \omega_{r}^{2}+0.0107622 \omega_{r}, v_{w}=11.5 \mathrm{~m} / \mathrm{s}
\end{gathered}
$$

\subsubsection{The Designed Power Curves}

Equation (13) provides the following designed $P_{e}-\omega_{r}$ curves under seven wind speeds, which are as follows:

$$
\begin{gathered}
P_{e}=-4.1741 \times 10^{-7} \omega_{r}^{3}+6.2612 \times 10^{-4} \omega_{r}^{2}, v_{w}=5.5 \mathrm{~m} / \mathrm{s} \\
P_{e}=-4.1741 \times 10^{-7} \omega_{r}^{3}+7.096 \times 10^{-4} \omega_{r}^{2}, v_{w}=6.5 \mathrm{~m} / \mathrm{s} \\
P_{e}=-4.1741 \times 10^{-7} \omega_{r}^{3}+7.93 \times 10^{-4} \omega_{r}^{2}, v_{w}=7.5 \mathrm{~m} / \mathrm{s}
\end{gathered}
$$




$$
\begin{gathered}
P_{e}=-4.1741 \times 10^{-7} \omega_{r}^{3}+8.7656 \times 10^{-4} \omega_{r}^{2}, v_{w}=8.5 \mathrm{~m} / \mathrm{s} \\
P_{e}=-4.1741 \times 10^{-7} \omega_{r}^{3}+9.6 \times 10^{-4} \omega_{r}^{2}, v_{w}=9.5 \mathrm{~m} / \mathrm{s} \\
P_{e}=-4.1741 \times 10^{-7} \omega_{r}^{3}+1.043 \times 10^{-3} \omega_{r}^{2}, v_{w}=10.5 \mathrm{~m} / \mathrm{s} \\
P_{e}=-4.1741 \times 10^{-7} \omega_{r}^{3}+1.127 \times 10^{-3} \omega_{r}^{2}, v_{w}=11.5 \mathrm{~m} / \mathrm{s}
\end{gathered}
$$

\section{Load Wind PMSG}

\subsection{Wind PMSG}

- The employed PMSG is rated as three-phase 4-pole, $4500 \mathrm{rpm}, 1.7 \mathrm{~kW}$, and $3.92 \mathrm{~N} \cdot \mathrm{m}$. The estimated data are as follows: peak value of flux linkage $\lambda_{m}^{\prime}=0.13 \mathrm{~Wb}$, phase winding resistance $R_{s}=0.73 \Omega$, q-axis inductance $L_{q}=7.031 \mathrm{mH}$, and d-axis inductance $L_{d}=4.2 \mathrm{mH}$, which belongs to interior PMSG (IPMSG). Further, the average winding inductance $L_{s}=\left(L_{q}+L_{d}\right) / 2=5.62 \mathrm{mH}$.

- Position sensing scheme: Incremental encoder has $(A, B, Z)$ signals with 1000 pulses/rev.

- Voltage and current sensing factors: $K_{v}=0.0025 \mathrm{~V} / \mathrm{V}$ and $K_{i}=0.043 \mathrm{~V} / \mathrm{A}$.

\subsection{PMSG Followed Three-phase Vienna SMR}

\subsubsection{Power Circuit}

The key features of the Vienna SMR are:

- Three-phase AC inputs: Equal to the back-EMFs of the employed IPMSG with $E_{a s}=25.71$ $V_{\text {rms }} / \mathrm{krpm}$, which changes with rotor speed.

- Output: $V_{d}=400 \mathrm{~V}, P_{d}=1.5 \mathrm{~kW}$.

- Energy storage inductors: Employing the PMSG embedded armature winding inductances as the Vienna boost inductors.

- $C_{d 1}=C_{d 2}=2200 \mu \mathrm{F} / 450 \mathrm{~V}$.

- PWM switching frequency: $f_{s}=30 \mathrm{kHz}$.

- Power devices: The rectifier module VUN 25-05E $\left(500 \mathrm{~V}, I_{D 25}=35 \mathrm{~A}\left(25^{\circ} \mathrm{C}\right), I_{D 85}=25 \mathrm{~A}\right.$ $\left(85^{\circ} \mathrm{C}\right), I_{D M}=95 \mathrm{~A}($ pulsed $\left.)\right)$ manufactured by IXYS.

\subsubsection{Control Schemes}

Commutation scheme. As shown in Figure 6, to achieve better SMR control characteristics, the current-command is generated by the unit vectors, synchronized with the IPMSG-generated back electromotive forces based on the sensed rotor position. The developed torque of an IPMSG is as follows:

$$
T_{e}=\frac{3}{2} \frac{P}{2}\left[\lambda_{m}^{\prime} \hat{I}_{a s} \cos \beta+\left(\frac{L_{d}-L_{q}}{2}\right) \hat{I}_{a s}^{2} \sin 2 \beta\right]
$$


where $\hat{I}_{a s}=\sqrt{i_{q s}^{2}+i_{d s}^{2}}$ and $\beta$ denotes the shifted angle of a-phase current phasor relative to the sensed q-axis. To achieve the maximum developed torque, $\partial T_{e} / \partial \beta=0$ can yield the commutation shift angle as follows:

$$
\beta=\beta_{\text {max }}=\sin ^{-1} \frac{-\lambda_{m}^{\prime}+\sqrt{\lambda_{m}^{\prime 2}+8\left(L_{q}-L_{d}\right)^{2} \hat{I}_{a s}^{2}}}{4\left(L_{q}-L_{d}\right) \hat{I}_{a s}}
$$

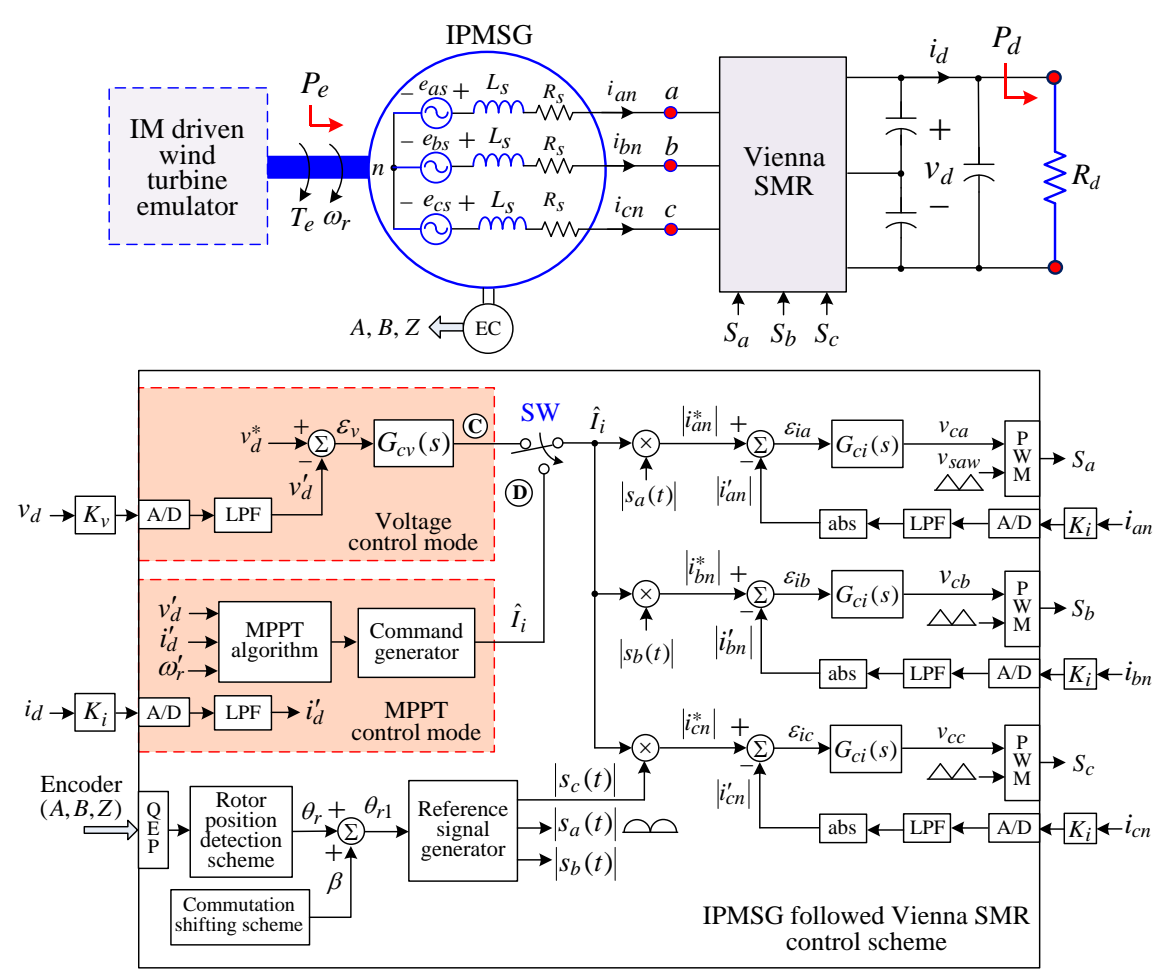

Figure 6 Control scheme of the IPMSG followed Vienna SMR.

\section{Current and Voltage Controllers.}

(i) Ramp-comparison current-controlled PWM scheme

Figure 6 depicts the ramp-comparison current-controlled PWM (RC-CCPWM) scheme, and the PI-type feedback controller is as follows:

$$
G_{c i}(s)=K_{P i}+\frac{K_{I i}}{s}
$$

The upper limit $K_{p i}$ using large-signal stability criterion is as follows:

$$
\frac{d v_{c o n t}}{d t}=K_{P i} K_{i} \frac{\left|V_{d}-\right| e_{a s}||}{L_{s}}<\frac{d v_{t r i}}{d t}
$$

The system parameters of the established Vienna SMR are $v_{d}=400 \mathrm{~V}, K_{i}=0.05 \mathrm{~V} / \mathrm{A}, f_{s}=$ $30 \mathrm{kHz}, L_{s}=5.62 \mathrm{mH}$, and $d v_{\text {tri }} / d t=60 \mathrm{kV} / \mathrm{s}$. Hence, the upper limit $K_{P i}$, from equation (23), by setting $e_{a s}=0 \mathrm{~V}$ is as follows: 


$$
K_{P i}<\left(\bar{K}_{P i}=\frac{d v_{t r i}}{d t} \times \frac{L_{s}}{V_{d} K_{i}}=16.89\right)
$$

Accordingly, $K_{P i}=10.63$ and trial-and-error can design the integral gain yields:

$$
G_{c i}(s)=K_{P i}+\frac{K_{I i}}{s}=10.63+\frac{52}{s}
$$

The selected digital control sampling rate for the current-loop is $f_{s i}=30 \mathrm{kHz}$.

(ii) Voltage Feedback Controller

The control block depicted in Figure 7(a) approximately represents the voltage loop dynamic model of the Vienna SMR, with the sensing factor being denoted as:

$$
K_{v}(s)=\frac{K_{v}}{1+\tau_{v} s}=\frac{0.002}{1+1.32 \times 10^{-3} s} \approx K_{v}
$$

The selected digital control sampling rate of the voltage loop is $f_{s v}=3 \mathrm{kHz}$.

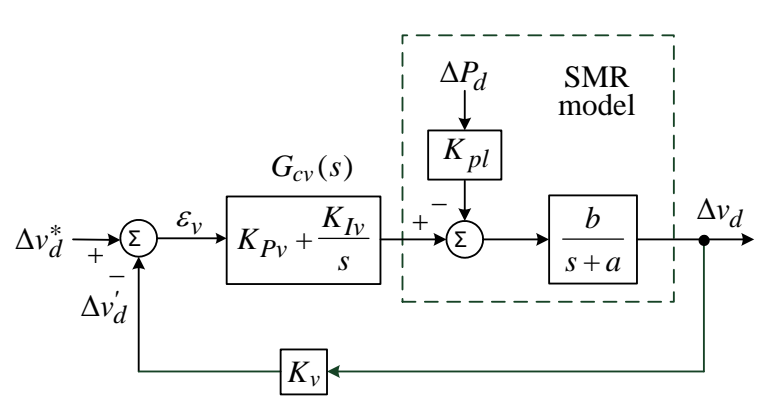

(a)

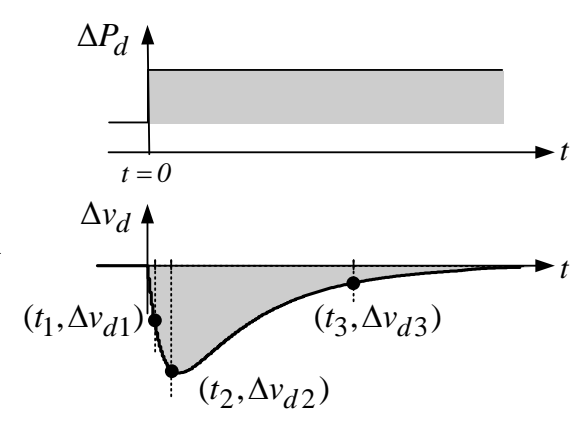

(b)

Figure 7 Voltage control loop dynamic model: (a) Control block diagram; (b) Desired voltage step regulation response.

The SMR dynamic model is approximately represented by the first-order process after filtering the high-frequency components of voltage ripples. Figure $7(b)$ sketches the desired voltage regulation response due to a step load power change. The labeled three typical points are $\left(t_{1}=\right.$ $\left.t_{f}, \Delta v_{d c 1}=0.5 \Delta v_{d m}\right),\left(t_{2}=t_{m}, \Delta v_{d c 2}=\Delta v_{d m}\right)$, and $\left(t_{3}=t_{r e}, \Delta v_{d c 3}=0.1 \Delta v_{d m}\right)$ with $t_{f}=$ falling time, $t_{m}=$ maximum dip occurred time, $t_{r e}=$ restoration time, and $\Delta v_{d m}=$ maximumvoltage dip.

The brief design procedure is as follows:

- Dynamic model estimation

The SMR operates stably for $\left(v_{d}=400 \mathrm{~V}, R_{d}=300 \Omega\right)$. Figure $7(\mathrm{~b})$ depicts the response shape of the PI voltage feedback controller $G_{c v}(s)=K_{P v}+K_{I v} / s=1+10 / s$. The $v_{d}$ due to a load change $R_{d}=300 \Omega \rightarrow 187.5 \Omega\left(\Delta P_{d}=320 \mathrm{~W}\right)$ is measured, and the three response points $(-14.4 \mathrm{~V}$, $29 \mathrm{~ms}),(-28.8 \mathrm{~V}, 132.5 \mathrm{~ms})$, and $(-2.9 \mathrm{~V}, 860 \mathrm{~ms})$ are employed to derive the following dynamic model parameters of the SMR:

$$
K_{p l}=5.296 \times 10^{-4}, a=5.46053, b=3738.84
$$


- Controller quantitative design

At the given operating point $v_{d}=400 \mathrm{~V}$ and $R_{d}=300 \Omega$, the voltage regulation control specifications are $\Delta v_{m}=10.5 \mathrm{~V}$ and $t_{r e}=0.56 \mathrm{~s}$ for a step power change of $\Delta P_{d}=320 \mathrm{~W}\left(R_{d}=\right.$ $300 \Omega \rightarrow 187.5 \Omega$ ). The careful derivation can obtain the following PI feedback controller:

$$
G_{c v}(s)=K_{P v}+\frac{K_{I v}}{s}=5.8+\frac{30}{s}
$$

Figures 8 (a) and 8 (b) compares the simulated and measured $v_{d}$ due to the similar load resistance change $R_{d}=300 \Omega \rightarrow 187.5 \Omega$. The closeness of the results is apparent.

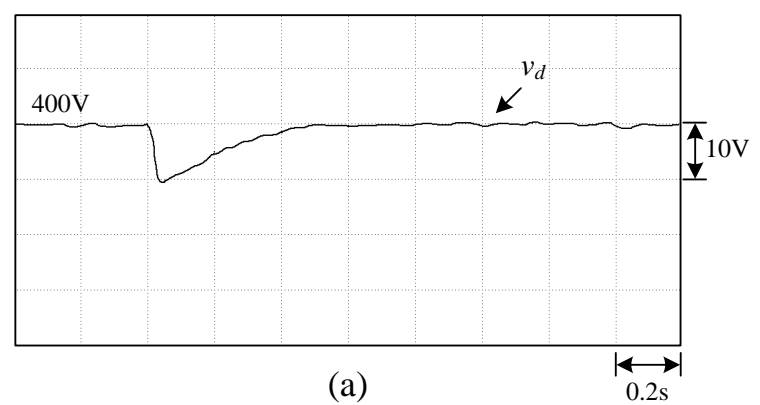

(a)

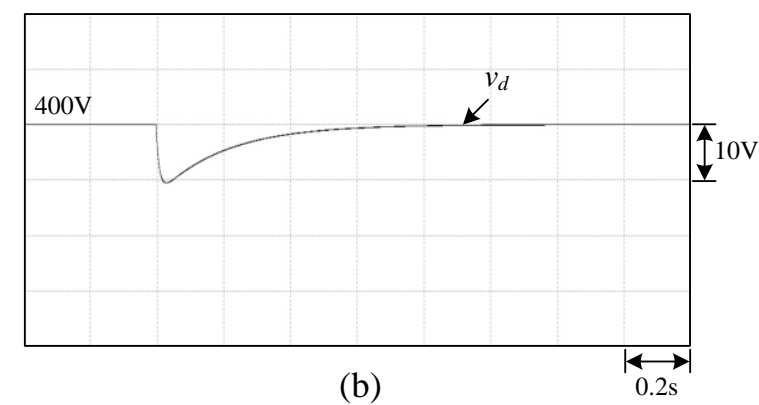

(b)

Figure 8 Voltage response of the developed Vienna SMR due to a load resistance change of $R_{d}=300 \Omega \rightarrow 187.5 \Omega$ by quantitatively designed controller $G_{c v}(s)=5.8+30 / s$ : (a) Measured result; (b) Simulated result.

\subsection{MPPT Control Scheme}

The Vienna SMR DC-link output power $P_{d}^{\prime}$ is observed and used for making the MPPT control. It is obtained as $P_{d}^{\prime}=v_{d}^{\prime} i_{d}^{\prime}$ with the sensing factors set as $K_{i}=0.2 \mathrm{~V} / \mathrm{A}$ and $K_{v}=0.00222 \mathrm{~V} / \mathrm{V}$.

The Perturb and Observe (P\&O) control with variable step size using the SMR current command $\hat{I}_{i}$ as a control variable are made according to the changes of $P_{d}$ and rotor speed.

As shown in Figure 9, the MPPT algorithm is judged one time per second, and the linguistic rules are as follows: (i) Case 1: The generated power rises, and rotor speed decreases to let $d \hat{I}_{i}>0$. (ii) Case 2: The generated power decreases, and rotor speed decreases to let $d \hat{I}_{i}<0$. (iii) Case 3: The generated power decreases, and rotor speed increases to let $d \hat{I}_{i}<0$. (iv) Case 4: The generated power decreases, and rotor speed increases to let $d \hat{I}_{i}>0$. (v) Case 5: The generated power remains unchanged, and thereby, letting $d \hat{I}_{i}=0$.

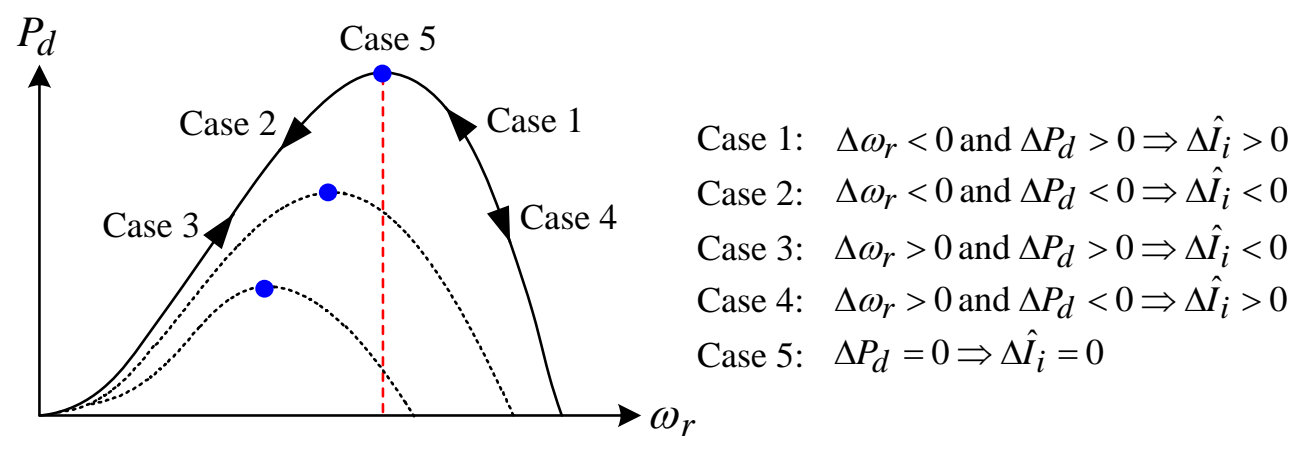

Figure 9 The proposed MPPT algorithm for determining the $\Delta \hat{I}_{i}$ Vienna SMR. 


\section{Experimental Results}

\subsection{IFO IM Drive Speed-mode Characteristics}

The switch in Figure 4 is at position (A) that allows the developed IFO IM drive to be operational under the speed mode. Figure 10(a) shows the measured $\left(\omega_{r}^{*}, \omega_{r}^{\prime}\right)$ and $\left(i_{q s}^{*}, i_{q s}^{\prime}\right)$ during the starting process $\left(\omega_{r}^{*}=0 \rightarrow 1800 \mathrm{rpm}\right)$ with the ramping rates of $225 \mathrm{rpm} / \mathrm{s}$ and $450 \mathrm{rpm} / \mathrm{s}$ at $\left(v_{d c}=400 \mathrm{~V}\right.$, $R_{d}=10 \Omega$ ). Figure $10(\mathrm{~b})$ depicts the measured $\left(\omega_{r}^{*}, \omega_{r}^{\prime}\right)$ and $\left(i_{q s}^{*}, i_{q s}^{\prime}\right)$ at $\omega_{r}^{*}=1800 \mathrm{rpm}, v_{d c}=400 \mathrm{~V}$, and $R_{d}=85.7 \Omega$, due to a step speed command change of $100 \mathrm{rpm}$. Further, Figure 10(c) depicts the measured $\left(\omega_{r}^{*}, \omega_{r}^{\prime}\right)$ and $\left(i_{q s}^{*}, i_{q S}^{\prime}\right)$ at $\left(\omega_{r}^{*}=1800 \mathrm{rpm}, v_{d c}=400 \mathrm{~V}, R_{d}=50 \Omega\right)$ due to a step load resistance change from $R_{d}=50 \Omega$ to $33 \Omega$. The results depict superior driving performances.

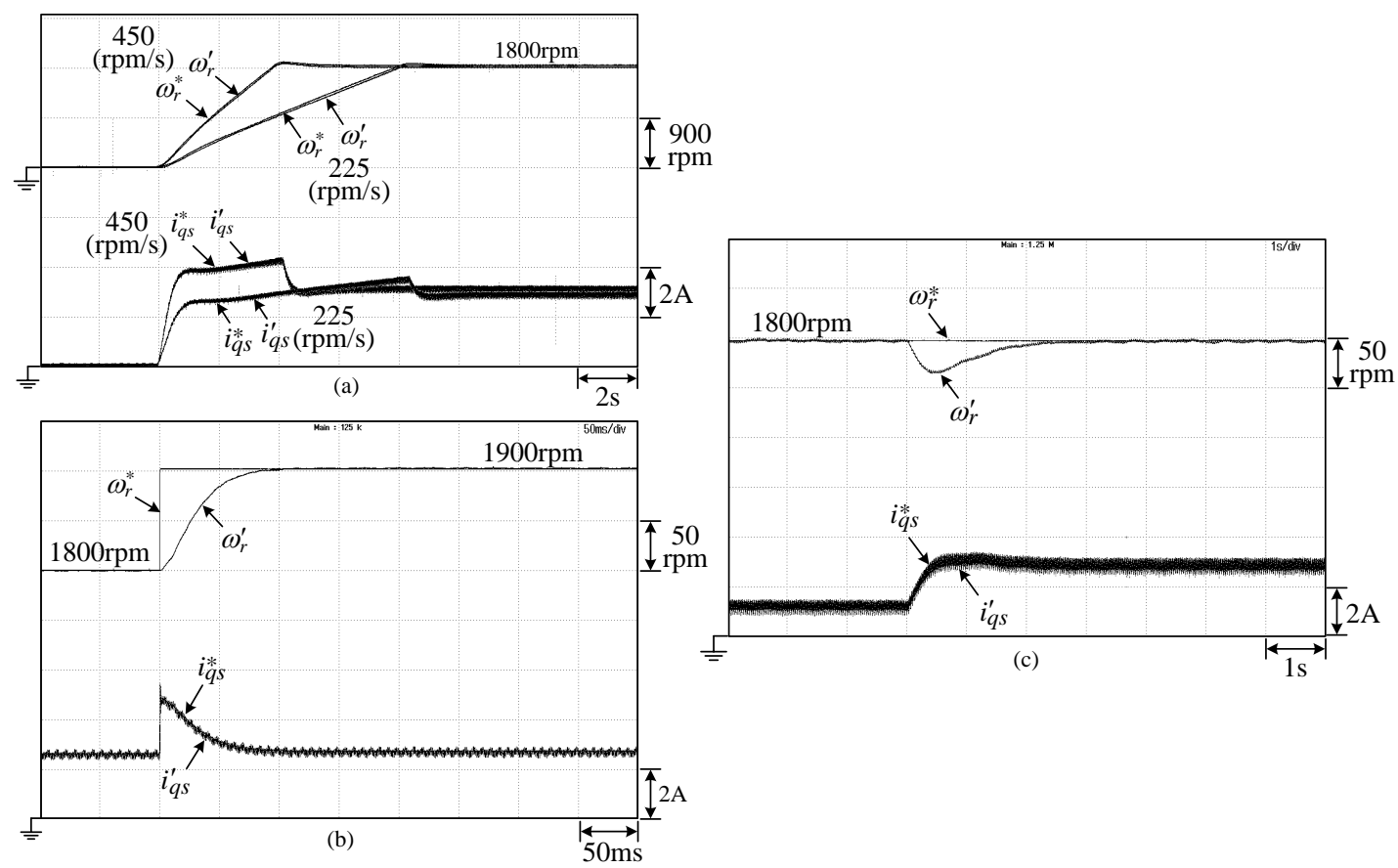

Figure 10 Measured dynamic responses of the established IFO IM drive: (a) $\left(\omega_{r}^{*}, \omega_{r}^{\prime}\right)$ and $\left(i_{q s}^{*}, i_{q S}^{\prime}\right)$ during starting process $\left(\omega_{r}^{*}=0 \rightarrow 1800 \mathrm{rpm}\right)$ with the rates of $225 \mathrm{rpm} / \mathrm{s}$ and $450 \mathrm{rpm} / \mathrm{s}$ at $\left(v_{d c}=400 \mathrm{~V}, R_{d}=10 \Omega\right)$; (b) $\left(\omega_{r}^{*}, \omega_{r}^{\prime}\right)$ and $\left(i_{q s}^{*}, i_{q s}^{\prime}\right)$ at $\left(\omega_{r}^{*}=1800 \mathrm{rpm}\right.$, $\left.v_{d c}=400 \mathrm{~V}, R_{d}=85.7 \Omega\right)$ due to a step speed command change of $100 \mathrm{rpm}$; (c) $\left(\omega_{r}^{*}, \omega_{r}^{\prime}\right)$ and $\left(i_{q s}^{*}, i_{q s}^{\prime}\right)$ at $\left(\omega_{r}^{*}=1800 \mathrm{rpm}, v_{d c}=400 \mathrm{~V}, R_{d}=50 \Omega\right)$ due to a step load resistance change from $R_{d}=50 \Omega$ to $33 \Omega$.

\subsection{IFO IM Driven Wind Turbine Emulated Characteristics}

The IM drive in torque mode is evaluated first. Figure 11 plots the measured torques and the resulting torque current commands of the IFO IM drive $\left(R_{d}=120 \Omega\right)$ due to a step torque command change $T_{e}^{*}=2 \mathrm{Nm} \rightarrow 3 \mathrm{~N} \cdot \mathrm{mby} \mathrm{PI}$ feedback control without and with torque robust tracking error cancellation control. The results indicate that the fast torque can be obtained by choosing the larger value of robust weighting factor $W_{T}$, subject to having larger torque current command. Taking the compromised considerations $W_{T}$ is 0.5 . 


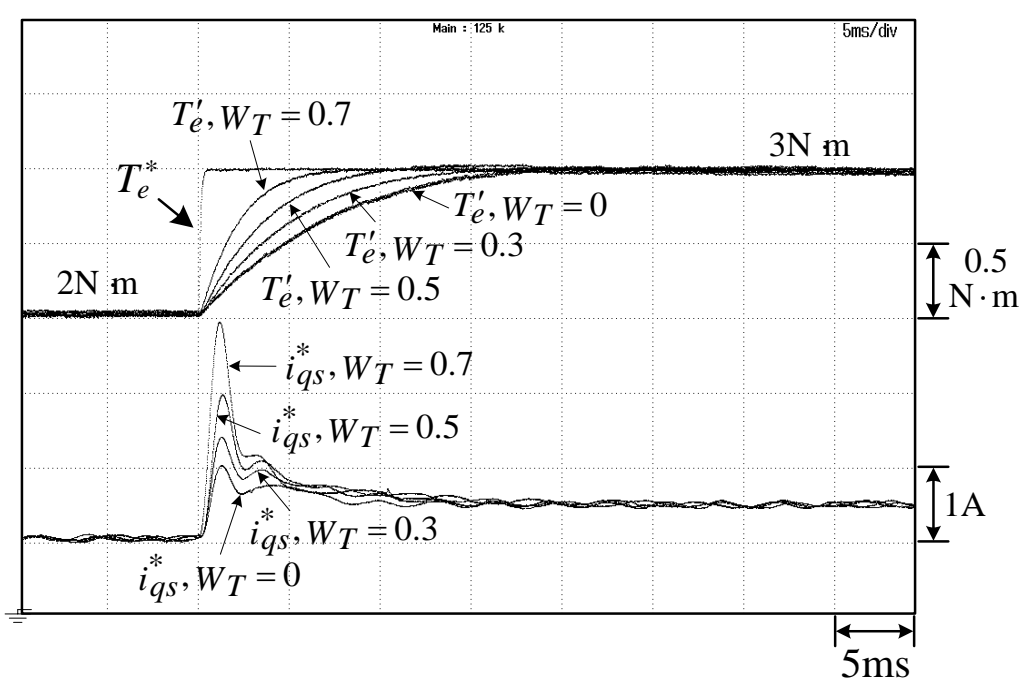

Figure 11 Measured torques and resultant torque current commands for the established IFO IM drive $\left(R_{d}=120 \Omega\right)$ due to a step torque command change $T_{e}^{*}=2 \mathrm{Nm} \rightarrow$ $3 \mathrm{Nmby} \mathrm{PI}$ feedback control without and with robust torque tracking error cancellation control.

The developed IFO IM-driven wind turbine emulator drives the IPMSG with Vienna SMR. The emulator follows the designed wind torque curve to present a desirable wind turbine driving behavior for the driven IPMSG.

Figure 12(a) shows the simulated torque curves for seven values $v_{w}$, and Figure 12 (b) depicts the simulated power curves. In Figure 12(a), the corresponding optimal (speed, torque) points are also labeled. As shown in Figure 12(a), since the generated torque is zero at a standstill, it is started from the speed-control mode and then changed to the torque-control mode. When the control mode is set at toque-control mode, the torque current command $i_{q s}^{*}$ signal changes from (A) to (B) as depicted in Figure 4.

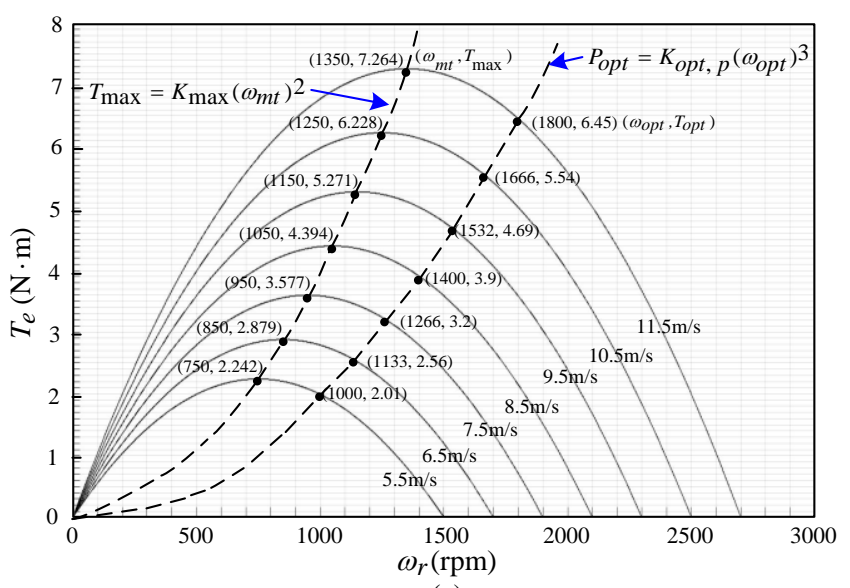

(a)

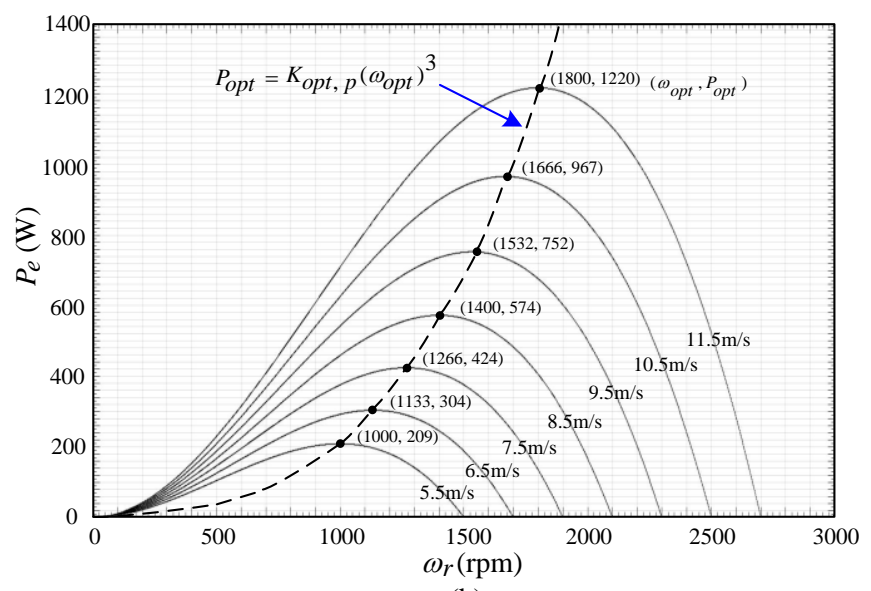

(b)

Figure 12 Simulated torque and power curves of the designed IFO IM-driven wind turbine emulator: (a) $T_{e}-\omega_{r}$; (b) $P_{e}-\omega_{r}$. 
Under the same conditions, Figures 13(a) and 13(b) depict the measured results of the established IFO IM-driven wind turbine emulator. Accordingly, closeness between measured and simulated results and the correctness of the designed wind turbine emulator are seen.

Comments: Figures 12 and 13 show the simulated and measured results and indicate the following facts: (i) Simulations verify the designed wind turbine torque-speed and power-speed results. (ii) The measured values show that respective errors are lower than $1.5 \%$ (at 950rpm, (3.577-3.53)/3.577=1.314\%) and 1.0\% (at 1266rpm, (424-420)/424=0.943\%) for the torque and the power compared to the designed ones.

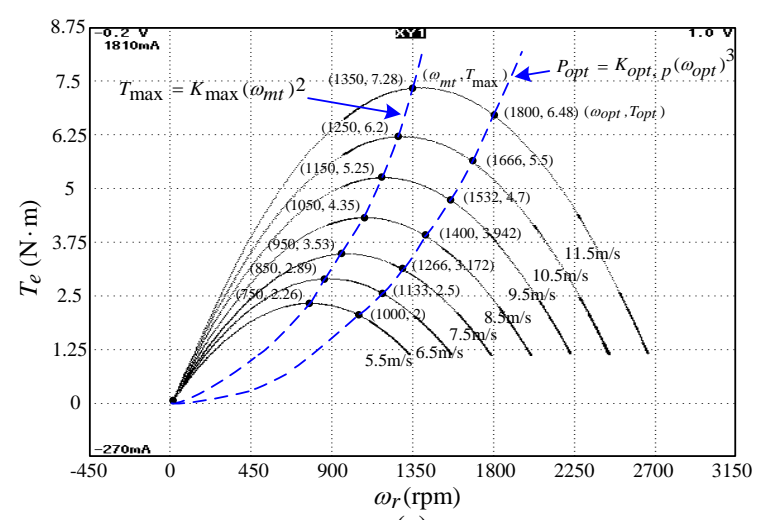

(a)

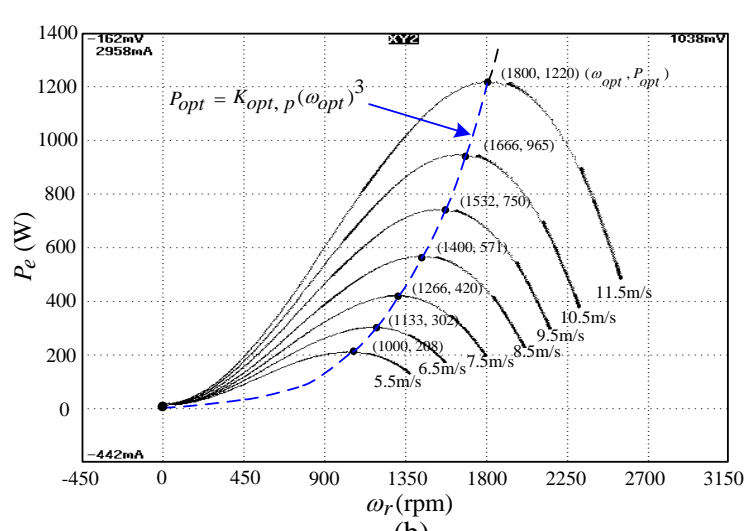

(b)

Figure 13 Measured torque and power curves of the established IFO IM-driven wind turbine emulator: (a) $T_{e}-\omega_{r}$; (b) $P_{e}-\omega_{r}$.

\subsection{IPMSG Operating Characteristics}

To evaluate the MPPT control, the switch SW in Figure 6 is set at position to determine the Vienna SMR current command $\hat{I}_{i}$ by the MPPT control scheme. The wind turbine emulator operates under the torque-speed mode, and the taking wind speed is $v_{w}=8.5 \mathrm{~m} / \mathrm{s}$. Figures $14(\mathrm{a})$ and $14(\mathrm{~b})$ show the measured $\left(\omega_{r}^{\prime}, P_{e}, T_{e}\right)$ and $\left(v_{d}, i_{d}, P_{d}, i_{a n}\right)$ at $R_{d}=85.74 \Omega$. Figures $15(\mathrm{a})$ and $15(\mathrm{~b})$ depict the results under $v_{w}=9.5 \mathrm{~m} / \mathrm{s}$ and $R_{d}=85.74 \Omega$. After several steps of the tuning process, the results indicate that the generated power by the wind turbine emulator converges at the maximum power points. The rotor speeds and the generated torques controlling are near the designed levels. On the generator side, the armature current generates maximum power for the connected load, and this verifies the correctness of the proposed MPPT control.

The wind speed changes from $v_{w}=9.5 \mathrm{~m} / \mathrm{s}$ to $v_{w}=8.5 \mathrm{~m} / \mathrm{s}$, and Figures $16(\mathrm{a})$ and $16(\mathrm{~b})$ show the measured $\left(\omega_{r}^{\prime}, P_{e}, T_{e}\right)$ and $\left(v_{d}, i_{d}, P_{d}, i_{a n}\right)$ under the dynamic MPPT tracking operation. It also presents superior dynamic tracking characteristics. 

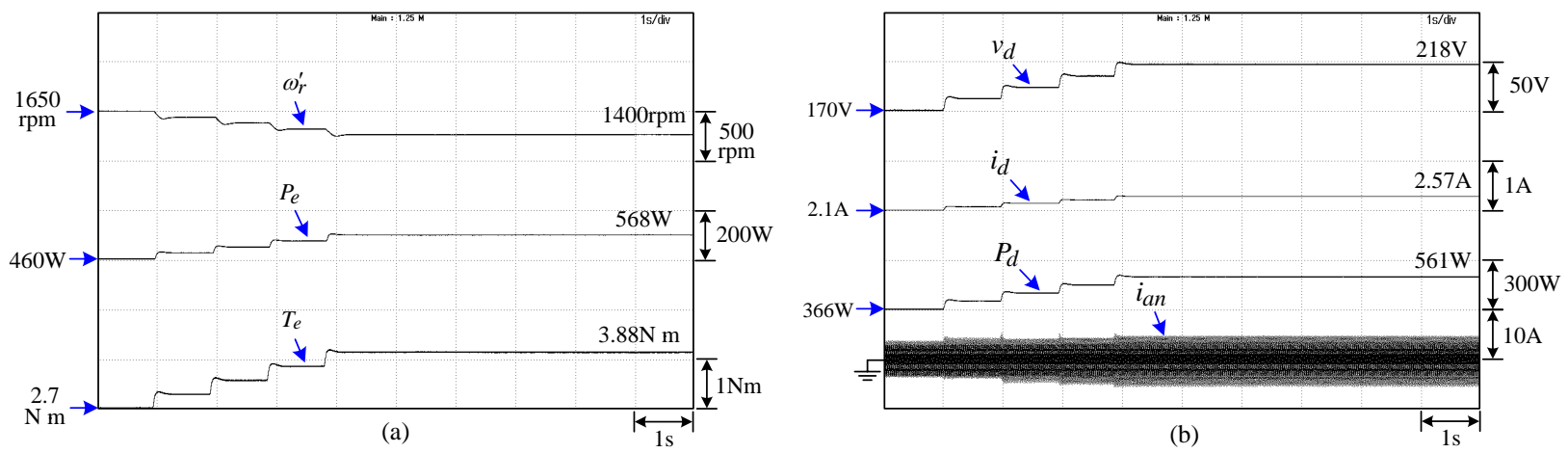

Figure 14 Measured results of the developed wind turbine emulator-driven IPMSG system under $\left(v_{w}=8.5 \mathrm{~m} / \mathrm{s}, R_{d}=85.74 \Omega\right)$ : (a) $\left(\omega_{r}^{\prime}, P_{e}, T_{e}\right)$; (b) $\left(v_{d}, i_{d}, P_{d}, i_{a n}\right)$.
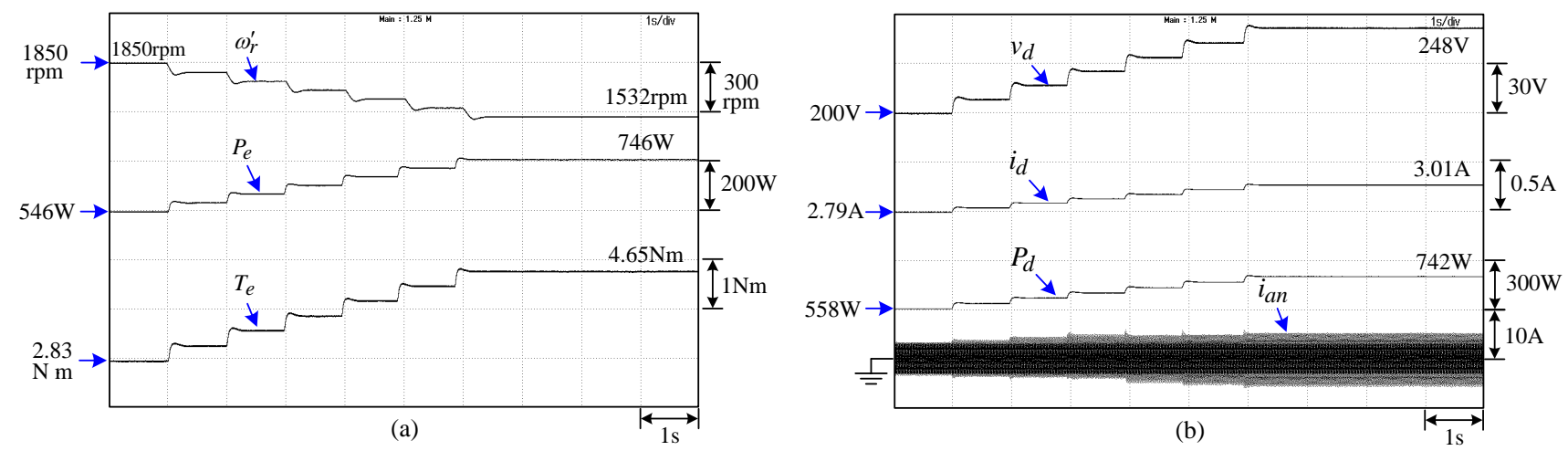

Figure 15 Measured results of the developed wind turbine emulator-driven IPMSG system under $\left(v_{w}=9.5 \mathrm{~m} / \mathrm{s}, R_{d}=85.74 \Omega\right)$ : (a) $\left(\omega_{r}^{\prime}, P_{e}, T_{e}\right)$; (b) $\left(v_{d}, i_{d}, P_{d}, i_{a n}\right)$.

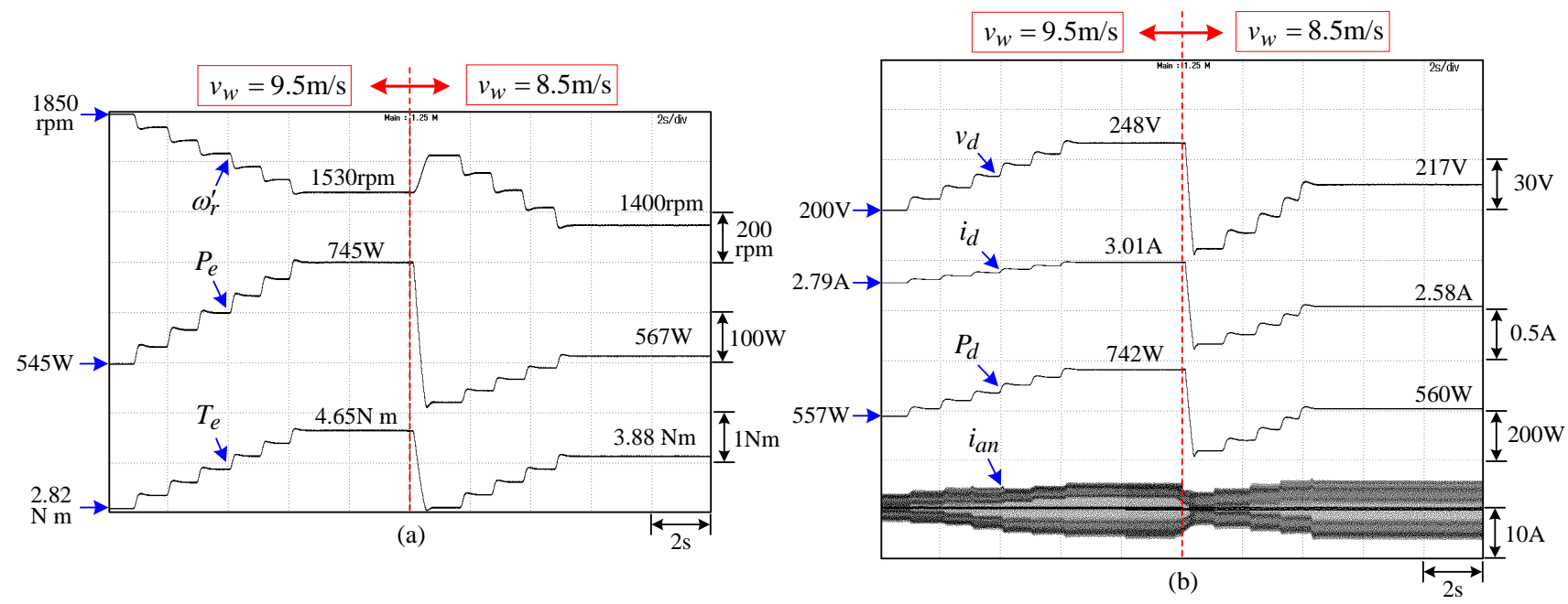

Figure 16 Measured dynamic MPPT tracking characteristics of the developed wind turbine emulator driven IPMSG system due to the wind speed change from $v_{w}=$ $9.5 \mathrm{~m} / \mathrm{s}$ to $v_{w}=8.5 \mathrm{~m} / \mathrm{s} \mathrm{(a)}\left(\omega_{r}^{\prime}, P_{e}, T_{e}\right) ;$ (b) $\left(v_{d}, i_{d}, P_{d}, i_{a n}\right)$. 


\section{Conclusions}

Wind turbine emulator is beneficial for conducting research on micro-grid. This paper presented the development of a wind turbine emulator using IFO IM drive. The desirable IM driving characteristics are preserved by properly treating its field-orientation mechanism with accurate rotor parameters and applying robust torque control. The conventional prime mover speed mode and the wind turbine torque-speed mode can be successfully operated by the developed IM driven emulator. The developed wind turbine emulator can be used to drive any type of generator. A test load with IPMSG followed by a three-phase Vienna SMR has been established and driven by the turbine emulator to establish the DC micro-grid common DC-bus voltage. Various wind turbine torque-speed characteristic curves under different wind speeds can be correctly generated by the developed wind turbine emulator. The designed results were verified by simulations, which indicated that the errors are within $1.5 \%$ and $1.0 \%$, respectively, for the torque and power, compared to the designed ones. The MPPT for extracting the wind generating power can be achieved by the IPMSG followed by Vienna SMR using the P\&O control approach. The effectiveness of the developed whole emulator has been verified experimentally, including its dynamic MPPT tracking operating characteristics.

\section{Author Contributions}

Yi-Chun Hsu: Main author involving the measurements and the paper writing; Min-Ze Lu: Assisting the author and doing the proofreading; Chang-Ming Liaw: Advisor giving suggesting and doing the proofreading.

\section{Competing Interests}

The authors have declared that no competing interests exist.

\section{References}

1. Anaya-Lara O, Jenkins N, Ekanayake JB, Cartwright P, Hughes M. Wind energy generation: Modelling and control. Chichester: John Wiley \& Sons; 2011.

2. De Matos JG, e Silva FS, Ribeiro LA. Power control in AC isolated microgrids with renewable energy sources and energy storage systems. IEEE Trans Ind Electron. 2014; 62: 3490-3498.

3. Dragičević $\mathrm{T}$, Lu X, Vasquez JC, Guerrero JM. DC microgrids-Part II: A review of power architectures, applications, and standardization issues. IEEE Trans Power Electron. 2015; 31: 3528-3549.

4. Ma T, Cintuglu MH, Mohammed OA. Control of a hybrid AC/DC microgrid involving energy storage and pulsed loads. IEEE Trans Ind Appl. 2016; 53: 567-575.

5. Mohamed MA, Diab AA, Rezk H, Jin T. A novel adaptive model predictive controller for load frequency control of power systems integrated with DFIG wind turbines. Neural Comput Appl. 2020; 32: 7171-7181.

6. Mohamed MA, Jin T, Su W. An effective stochastic framework for smart coordinated operation of wind park and energy storage unit. Appl Energy. 2020; 272: 115228.

7. Wang P, Wang D, Zhu C, Yang Y, Abdullah HM, Mohamed MA. Stochastic management of hybrid AC/DC microgrids considering electric vehicles charging demands. Energy Rep. 2020; 6: 1338- 
1352.

8. Lan T, Liu X, Wang S, Jermsittiparsert K, Alrashood ST, Rezaei M, et al. An advanced machine learning based energy management of renewable microgrids considering hybrid electric vehicles' charging demand. Energies. 2021; 14: 569.

9. Blaabjerg F, Ma K. Future on power electronics for wind turbine systems. IEEE Trans Emerg Sel Topics Power Electron. 2013; 1: 139-152.

10. Guerrero JM, Lumbreras C, Reigosa DD, Garcia P, Briz F. Control and emulation of small wind turbines using torque estimators. IEEE Trans Ind Appl. 2017; 53: 4863-4876.

11. Llano DX, McMahon RA. Control techniques with system efficiency comparison for microwind turbines. IEEE Trans Sustain Energy. 2017; 8: 1609-1617.

12. Karabacak M, Fernández-Ramírez LM, Kamal T, Kamal S. A new hill climbing maximum power tracking control for wind turbines with inertial effect compensation. IEEE Trans Ind Electron. 2019; 66: 8545-8556.

13. Mohammadi E, Fadaeinedjad R, Naji HR, Moschopoulos G. Investigation of horizontal and vertical wind shear effects using a wind turbine emulator. IEEE Trans Sustain Energy. 2018; 10: 1206-1216.

14. Krause PC, Wasynczuk O, Sudhoff SD, Pekarek S. Analysis of electric machinery and drive systems. 3rd ed. New York: IEEE press; 2002.

15. Buyukdegirmenci VT, Bazzi AM, Krein PT. Evaluation of induction and permanent-magnet synchronous machines using drive-cycle energy and loss minimization in traction applications. IEEE Trans Ind Appl. 2013; 50: 395-403.

16. Tammaruckwattana S, Ohyama K. Experiment verification of variable wind speed power generation system using permanent magnet synchronous generator by wind turbine emulator. Proceedings of the IEEE IES; 2012 October 25th; Montreal, QC, Canada. Piscataway Township: Institute of Electrical and Electronics Engineers.

17. Averous NR, Stieneker M, Kock S, Andrei C, Helmedag A, De Doncker RW, et al. Development of a $4 \mathrm{MW}$ full-size wind-turbine test bench. IEEE Trans Emerg Sel Topics Power Electron. 2017; 5: 600-609.

18. Kojabadi HM, Chang L, Boutot T. Development of a novel wind turbine simulator for wind energy conversion systems using an inverter-controlled induction motor. IEEE Trans Energy Convers. 2004; 19: 547-552.

19. Nye JM, De La Bat JG, Khan MA, Barendse P. Design and implementation of a variable speed wind turbine emulator. Proceedings of the IEEE ICEM; 2012 September 2nd; Marseille, France. Piscataway Township: Institute of Electrical and Electronics Engineers.

20. Henz G, Koch G, Franchi CM, Pinheiro H. Development of a variable speed wind turbine emulator for research and training. Proceedings of the IEEE COBEP; 2013 October 27th; Gramado, Brazil. Piscataway Township: Institute of Electrical and Electronics Engineers.

21. Gontijo G, Krejci D, Guedes S, Tricarico T, França B, Aredes M. Implementation of a wind turbine emulator test bench using a squirrel cage induction machine. Proceedings of the IEEE COBEP; 2017 November 19th; Juiz de Fora, Brazil. Piscataway Township: Institute of Electrical and Electronics Engineers.

22. Sombra AK, Sgrò D, Leao RP, Sampaio RF, Sampaio FC. Modeling and simulation of an emulator of a wind turbine using vector speed control of a three-phase induction motor. Proceedings of the 2018 Simposio Brasileiro de Sistemas Eletricos (SBSE); 2018 May 12nd; Niteroi, Brazil. 
Piscataway Township: Institute of Electrical and Electronics Engineers.

23. Nair R, Narayanan G. Emulation of wind turbine system using vector controlled induction motor drive. IEEE Trans Ind Appl. 2020; 56: 4124-4133.

24. Trzynadlowski AM. The field orientation principle in control of induction motors. Berlin: Springer Science \& Business Media; 2013.

25. Amezquita-Brooks L, Liceaga-Castro J, Liceaga-Castro E. Speed and position controllers using indirect field-oriented control: A classical control approach. IEEE Trans Ind Electron. 2013; 61: 1928-1943.

26. Zhao L, Huang J, Chen J, Ye M. A parallel speed and rotor time constant identification scheme for indirect field oriented induction motor drives. IEEE Trans Power Electron. 2015; 31: 64946503.

27. Teja AR, Chakraborty C, Maiti S, Hori Y. A new model reference adaptive controller for four quadrant vector controlled induction motor drives. IEEE Trans Ind Electron. 2011; 59: 37573767.

28. Zhang $\mathrm{Y}$, Yang $\mathrm{H}$. Model predictive torque control of induction motor drives with optimal duty cycle control. IEEE Trans Power Electron. 2014; 29: 6593-6603.

29. Lascu C, Jafarzadeh S, Fadali MS, Blaabjerg F. Direct torque control with feedback linearization for induction motor drives. IEEE Trans Power Electron. 2016; 32: 2072-2080.

30. García O, Cobos JA, Prieto R, Alou P, Uceda J. Single phase power factor correction: A survey. IEEE Trans Power Electron. 2003; 18: 749-755.

31. Kolar JW, Friedli T. The essence of three-phase PFC rectifier systems- part I. IEEE Trans Power Electron. 2013; 28: 176-198.

32. Hadj-Youssef NB, Al-Haddad K, Kanaan HY, Fnaiech F. Small-signal perturbation technique used for DSP-based identification of a three-phase three-level boost-type Vienna rectifier. IET Electr Power Appl. 2007; 1: 199-208.

33. Chen H, David N, Aliprantis DC. Analysis of permanent-magnet synchronous generator with Vienna rectifier for wind energy conversion system. IEEE Trans Sustain Energy. 2012; 4: 154163.

34. Rajaei A, Mohamadian M, Varjani AY. Vienna-rectifier-based direct torque control of PMSG for wind energy application. IEEE Trans Ind Electron. 2012; 60: 2919-2929.

35. Femia N, Petrone G, Spagnuolo G, Vitelli M. Optimization of perturb and observe maximum power point tracking method. IEEE Trans Power Electron. 2005; 20: 963-973.

36. Dalala ZM, Zahid ZU, Yu W, Cho Y, Lai JS. Design and analysis of an MPPT technique for smallscale wind energy conversion systems. IEEE Trans Energy Convers. 2013; 28: 756-767.

37. Uddin MN, Patel N. Maximum power point tracking control of IPMSG with loss minimization algorithm for wind energy conversion system. Proceedings of the 2013 IEEE Industry Applications Society Annual Meeting; 2013 October 6th; Lake Buena Vista, FL, USA. Piscataway Township: Institute of Electrical and Electronics Engineers.

38. Zou Y, Elbuluk M, Sozer Y. Stability analysis of maximum power point tracking (MPPT) method in wind power systems. IEEE Trans Ind Appl. 2013; 49: 1129-1136.

39. Hussain J, Mishra MK. Adaptive maximum power point tracking control algorithm for wind energy conversion systems. IEEE Trans Energy Convers. 2016; 31: 697-705. 


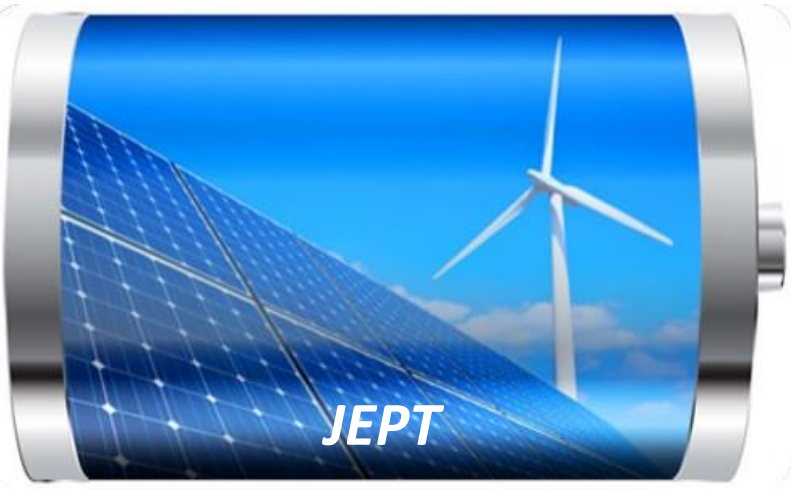

Enjoy JEPT by:

1. Submitting a manuscript

2. Joining in volunteer reviewer bank

3. Joining Editorial Board

4. Guest editing a special issue

For more details, please visit:

http://www.lidsen.com/journal/jept 